This is a self-archived version of an original article. This version may differ from the original in pagination and typographic details.

Author(s): Stark, Laura

Title: Why daughters may choose early marriage

Year: 2019

Version: Accepted version (Final draft)

Copyright: (c) Author, 2019

Rights: In Copyright

Rights url: http://rightsstatements.org/page//nC/1.0/?language=en

Please cite the original version:

Stark, L. (2019). Why daughters may choose early marriage. Nature Human Behaviour, 3(4), 325-326. https://doi.org/10.1038/s41562-019-0554-1 
(Author's final draft) Recommended citation: Stark, Laura. 2019. "Why Daughters may Choose Early Marriage", Nature Human Behaviour 3: 325-326.

\section{Why Daughters may Choose Early Marriage}

Laura Stark, Department of History and Ethnology, University of Jyväskylä, Finland

In 29 African countries, including Tanzania, rates of marriage before age 18 are over $30 \%$ [1]. Early marriage has raised substantial concerns regarding mental well-being, autonomy and childbirth-related complications that are the leading cause of death worldwide for girls aged 15 to 19 [23]. Because early marriage statistically correlates with lower education levels, it is also assumed that early marriage prevents girls from continuing their schooling. That early marriage can be harmful for girls is therefore undisputed. But are these harms universal and if so, why does early marriage persist? Child marriage statistics do little to answer this question. Claims by human rights campaigns and the media that under-18 marriages arise from lack of parents' commitment to girls' education and empowerment are based on two unexamined premises. The first is that when daughters marry young, it is because the parents are pursuing goals that are not in the daughters' best interests. The second is that under-18 marriage always involves-by definition-the girl's lack of consent.

Early marriage is a social phenomenon in which local understandings guide family decision-making, yet most research on early marriage is based on rapid evaluation instead of in-depth or repeat interviews. Drivers of early marriage are rarely disaggregated separately for urban and rural areas, and existing literature on the impacts of under-18 marriage rarely distinguishes between children, younger adolescents and older adolescents. Causes are often not distinguished from outcomes in statistically cooccurring factors. 'End child marriage' campaigns rarely examine or follow girls' life trajectories to see whether educational attainment, for example, would have been accessible, affordable, or influential on women's future life prospects. Moreover, few studies have systematically tested prevailing assumptions about early marriage.

In this issue of Nature Human Behaviour, Schaffnit and colleagues [4] do just this. Using a large-scale survey with supplementary focal group data in a rural area of northern Tanzania, they test whether parental interests and coercion explain the high incidence of female marriage for adolescents aged between 15 and 18, the ages between which the vast majority of early marriages occur in this region. They find that younger brides do generally receive a higher bridewealth and that girls with four or more older brothers tend to marry earlier, likely reflecting the need to pay bridewealth for their 
brothers' marriages. This suggesting that there is a benefit to parents when their daughters marry younger. However, in contradiction to a parent-offspring conflict model, they find no evidence that parents select husbands for their daughters; instead, the majority of daughters report having chosen their own marriage partner. They also find that women marrying in later adolescence do not appear to suffer obvious detriments to their physical or mental wellbeing later in life.

In contrast to the media portrayal of parents who marry off their daughters to strategically benefit themselves or other members of the family, it appears that locally high rates of early marriage in this region are likely to be driven by shared interests of parents and daughters. The authors conclude that young women are active agents in marriage decisions. Marriage increases young women's communal status and power in household decision-making and grants them adult privileges when childhood roles expire. Divorce and remarriage are also common within this context and so marriage represents a relatively low opportunity cost for under-18 girls when viewed across a lifetime.

The most important advance of this study for tackling women's empowerment is the finding that better alternatives to early marriage are rarely available in this study population. To focus on early marriage as the cause of women's disempowerment is to address the tail end of the problem rather than its core [5]. The work by Schaffnit and colleagues lends credibility to other findings in Tanzania that suggest educational opportunities can be closed off to girls before marriage [6] and that girls themselves, seeing this, choose to marry early [7]. The authors note that strong local norms prohibit marriage to schoolgirls, but that educational attainment is disrupted by high rates of premarital childbearing. This means that marriage itself is not necessarily the reason for dropping out of school. Instead, causality seems likely to run in the opposite direction: obstacles to attaining education and the low use-value of education make early marriage a more attractive — and possibly the only_option for girls' future prospects and social inclusion.

It is important to keep in mind that this study concerned mainly older adolescents and is therefore less informative about marriage at younger ages. Yet, as the authors point out, the overwhelming majority of so-called 'child marriages' across much of sub-Saharan Africa take place in late adolescence, highlighting the problem of lumping together marriages at different ages into the same international development targets. Future research that disaggregates data on age at first marriage will be crucial in determining impacts and mechanisms for different age groups.

The authors also point out that their data did not take into account mortality rates from childbirth complications among early-married women, thus potentially underestimating 
the costs of under-18 marriage to well-being. However, the fact that premarital pregnancy is widespread in Tanzania suggests that adolescent marriage alone would not account for such an increased risk even if found, since many girls become pregnant before 18 without being married. It seems likely that the prevalence of premarital pregnancy may itself be a major motivational factor in under-18 marriages, as families weigh the costs of their daughters raising children born out of wedlock [68]. At the same time, girls marrying under 18 but choosing their own partners suggests that some girls wish to marry early. Future research would do well to examine reasons for this.

The authors' research shows that using a large sample from a single localized and relatively homogeneous population is a powerful tool to address untested assumptions about early marriage, and it provides additional evidence in the debate about a universal 'consent boundary' at age 18 [9].

\section{Competing interests}

The author declares no competing interests.

\section{References}

1 .

UNICEF. State of the World's Children. https://www.unicef.org/sowc/ (2017).

2.

Save the Children. State of the World's Mothers 2004. (Save the Children, Westport, CT, USA, 2004).

3.

UNICEF. Ending Child Marriage: Progress and Prospects. (UNICEF, New York, 2014). 4.

Schaffnit, S., Hassan, A., Urassa, M. \& Lawson, D. Parent-offspring conflict unlikely to explain 'child marriage' in northwestern Tanzania. Nat. Hum. Behav. (2019).

5.

Archambault, C. Ethnographic empathy and the social context of rights: 'rescuing' Maasai girls from early marriage. Am. Anthropol. 113, 632-643 (2011).

6.

Tanzanian Ministry of Health, Community Development, Gender, Elderly and Children. National Survey on the Drivers and Consequences of Child Marriage in Tanzania. (Dar es Salaam, Tanzania 2017).

7.

Stark, L. Poverty, consent, and choice in early marriage: ethnographic perspectives from urban Tanzania. Marriage Fam. Rev. 54, 565-581 (2018). 
8.

Mulumeoderhwa, M. 'A girl who gets pregnant or spends the night with a man is no longer a girl': forced marriage in the eastern Democratic Republic of Congo. Sex. Cult. 20, 1042-1062 (2016).

9.

Bunting, A., Lawrance, B. \& Roberts, R. Introduction: something old, something new? Conceptualizing forced marriage in Africa". in Marriage by Force? Contestation over Consent and Coercion in Africa (eds. Bunting, A., Lawrance, B.N. \& Roberts, R.) 1-42 (Ohio University Press, Athens, OH, USA, 2016). 